\title{
Research on the Problems and Strategies of Agricultural Economic Development in Hubei Province
}

\author{
Liang Xuan \\ Yangtze University, Jingzhou, 434023, China
}

Keywords: Agricultural Economic Development; Problems; Strategies

\begin{abstract}
This paper expounded the related concepts of agricultural economy and summed up the problems of agricultural economic development in Hubei province. The results show that Hubei province needs to pay attention to the diagnosis analysis of agricultural economic development, to discover and summarize the existing shortage. Then, it is also necessary to correctly and comprehensively deal with these problems. In this way, the countermeasures can precisely and efficiently work. In fact, the problems of agricultural economic development in Hubei province are mainly focused on low-level agricultural technology, backward brand building, serious agricultural pollution and low-level industrialization, which seriously influence the developmental potential and quality of agricultural economy. At last, based on the current prominent problems, and combined with the actual situation in the area, this paper puts forward the countermeasures for the future development of Hubei's agricultural economy. Namely, the development of agricultural economy in Hubei needs to adhere to the road of scientific and technological agriculture, agricultural industrialization, scale management and ecological agriculture.
\end{abstract}

\section{Introduction}

Hubei is one of China's important agricultural province, with agriculture playing an important role in its economic and social development. with the continuous development of the times, a series of problems covered by the extensive development has started to expose, which brought a lot of constraints to the development of agricultural economy and finally make the agriculture plunged into development dilemma. [1] In other words, the agriculture is large but not robust. Under this background, Hubei province needs to attach great importance to the typical problems existing in the development of agricultural economy, make full use of the experience of other countries and regions, explore more in line with the law of development of Hubei agricultural economy, find the development path based on the actual situation, in order to achieve sustainable and healthy development of the local agricultural economy. [2]

\section{Agricultural economy}

China's agriculture has the meaning of broad and narrow sense. Narrowly speaking, it only refers to planting, forestry, animal husbandry, breaded. Broadly speaking, it is classified as the category of the first industry in our country, which is equal to the first industry. [3] The main manifestations of agricultural economic development include the steady increase of grain output, the continuous promotion of farmers' income, the improvement of agricultural industrialization and so on. [4] The main forms of agricultural economy include the overall ownership, the collective ownership, the private sector, the joint venture, the individual, the shares and the joint venture between China and foreign countries. The development of agricultural economy is essentially the revolution of agricultural development mode, which reflects the adjustment of agricultural productivity and relations of production. In terms of the change of agricultural development mode, it means to push forward from two aspects of productivity and production relations, enhance the production mainly relying on science and technology, introduce new technology in agricultural production, improve labor skills and stimulate productivity. [5] In terms of production relations, it means to adjust the ownership of means of production and distribution relationship by the system innovation. In fact, 
the healthy development of the agricultural economy is heavily dependent on science and technology progress and system innovation. It will influence the productivity and production relations coordination without any of them.

\section{Problems existing in the development of agricultural economy}

\subsection{The backward agriculture-related technology, low application of information technology and low-level quality of some labor}

At present, there is still a gap between the technology research of Hubei and the developed countries, and the popularization rate of agricultural machinery is still relatively low. Moreover, in Hubei Province, local farmers are not well educated; they know less about the relevant knowledge of agricultural products. Although the farmers cultivate for generations of agricultural products, they poorly understand the market, they cannot judge the actual benefits of agricultural products either according to market situation. In addition, it is worth noticing that the gap between urban and rural areas is large in Hubei province. Many farmers choose to work in cities not countryside. People who stick to farming at home is less and less. In this way, agricultural structure in Hubei is further undermined.

\subsection{Weak rural industrial organization, small production scale and poor income}

Hubei is a large province of agriculture; it has a vast territory. But in fact, the per capita planting area is low. This is especially evident in the planting of the south of Hubei province. In addition, the number of enterprises set up in rural and township is relatively small, plus the scale is also small, and the quality of management and the quality of staff can not keep pace with the times. Therefore, the lack of competition ability of sales will further influence the company's financing and investment income, which also further decline the attractiveness of a large number of rural labor force. At present, the Hubei province agriculture is still dominated by farming, with large percentage of traditional food crops and small percentage of economic crops. The lack of a more scientific management mode and production measures would lead to the difficult continuation of agricultural production of Hubei Province in today's society.

\subsection{The lack of agricultural production resources, the protection of ecological environment}

With the rapid development of the economy of Hubei Province, the environmental problems are becoming more and more prominent, and environmental protection work is imminent. At present, the reasons of environment problems mainly consist of large demand of human on environment, such as the excessive felling of trees, rampant deforestation, etc. These behaviors sharply reduced the crop planting area of Hubei province. At the same time, the industrial development has also caused a certain influence, industrial waste gas and waste water emissions caused air pollution and water pollution. With poor air quality and obvious greenhouse effect, the environment for crop growing is damaged, the harvest would naturally decrease year after year. More seriously, the decrease of water resources is a fatal blow to those crops which like water. In addition, soil erosion and deforestation caused by the decline of soil fertility, the environment for crop growing would be badly influenced. With the acceleration of urbanization in Hubei, the demand for land of building high-rise buildings is increasing. Much agricultural land has been designated as urban construction land, which reduces agricultural land and agricultural productivity.

\section{Development strategy of agricultural economy in Hubei Province}

The strategy of agricultural development in Hubei is to achieve the harmonious development of agricultural production and ecological environment and to form a coexistence development mode including harmonious development, fair development, efficiency and equity while satisfying the demand of human beings for agricultural products. It can be showed in Figure 1. 


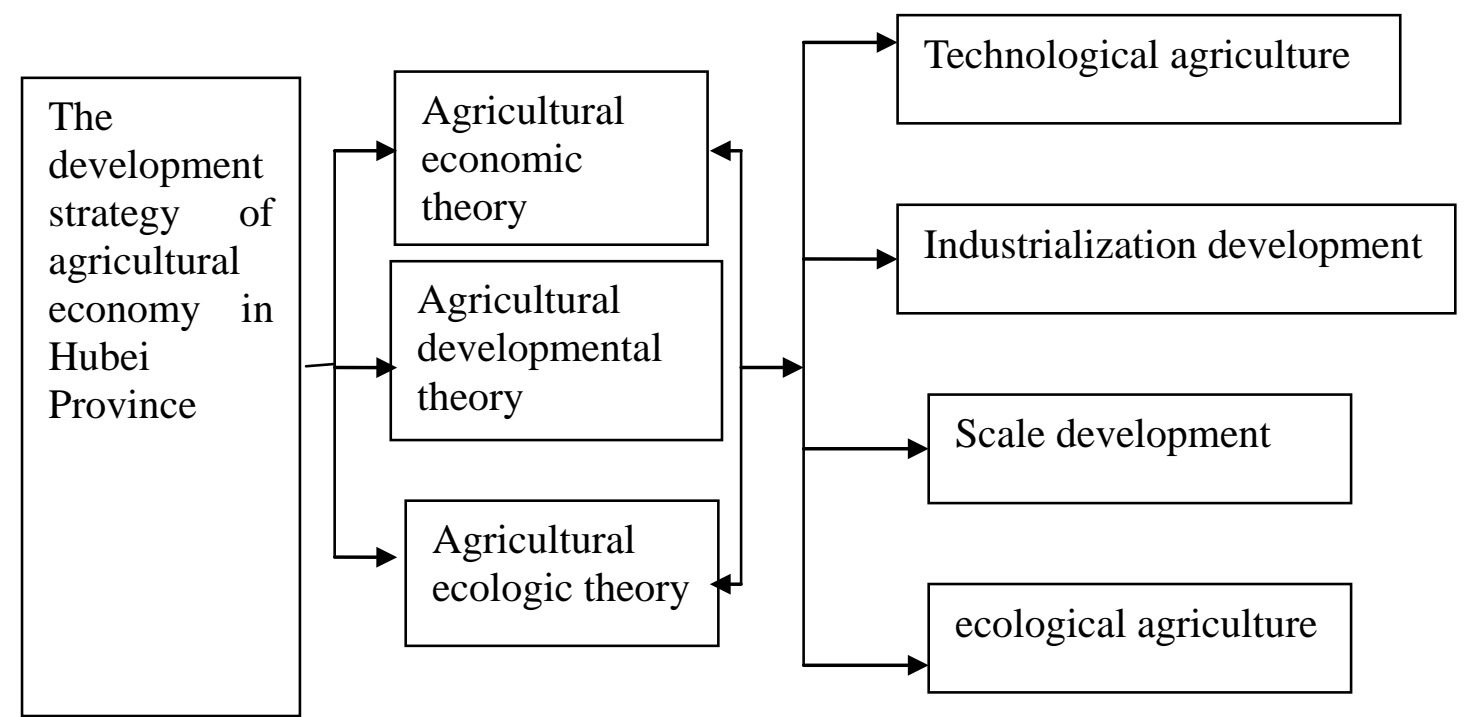

Figure 1 Model of agricultural economic development in Hubei Province

\subsection{Taking the road of technological agriculture}

The current reality of the overall low-level agricultural technology in Hubei has seriously endangered the healthy development of agricultural economy. Hubei province needs to strengthen the construction of agricultural technology extension system, improve the level of agricultural technology in an all-round way, and improve the technological content of agricultural products. One of the key points of the construction of the agricultural technology extension system in Hubei is to strengthen the construction of the talent team. The construction of agricultural technology needs to formulate long-term plan for talent team according to the needs of agricultural industrialization and modernization so as to break away from the bottleneck of building agricultural technology extension system and human resources team. To promote the construction of talent team in agricultural technology, on the one hand, we should strengthen the introduction of talents, provide stable remuneration and good development space to attract more talents to enter this industry. On the other hand, the continuing education and training of agricultural technology extension personnel should be strengthened. Hubei provincial government should strengthen the cooperation with relevant colleges and universities to cultivate talents according to the talents training program.

\subsection{Taking the road of industrialization agriculture}

The development of agricultural economy in Hubei province should take the way of industrialization. Through industrialization, we can achieve effective docking between small production and large market and expand the industrial chain of stretching agricultural products, so as to realize the development of agricultural economy. On the one hand, we should build a large number of agricultural leading enterprises to play the leading role. On the other hand, we should pay attention to the adjustment and improvement of the benefit distribution relationship between enterprises and farmers. We must establish the idea of cooperation and win-win. The interests of every main body in the whole agricultural industry management mode are not conflicting, but dependent on each other.

\subsection{Taking the road of scale agriculture}

Agricultural economy in Hubei needs to unswervingly stick the large scale development. Through large-scale operation, it can improve the efficiency of agricultural production, emancipate more rural surplus labor to enter other industries, and promote better economic and social development. First, we should actively promote the improvement of rural land transfer and achieve the scale of farming. For example, the government takes the lead to carry out orderly circulation of farmland, improve the land transfer system, standardize the rural land transfer market, and achieve 
the full development and utilization of these lands. Secondly, we should break the dual economic system as soon as possible, and achieve the free flow of labor and capital and other elements in urban and rural areas, especially for migrant workers who work in cities to successfully settle in cities. Thirdly, we should give more support to land cost operators to increase efforts in agricultural subsidies, seed subsidies, provide necessary credit support, give adequate technical guidance, and guide development and so on

\subsection{Taking the road of ecological agriculture}

The development of agricultural economy can not be built on the sacrifice of environment. Agricultural economy in Hubei province should implement the basic requirements of sustainable development and unswervingly stick to the ecological road to realize the sustainable development of agriculture. First of all, the government should strengthen the regulation of agricultural pollution control. Through the monitoring of agricultural products, pesticide production, use and sale, it can solve the safety problems of agricultural products and the great harm to the environment caused by the excessive use of pesticides. Secondly, the government should vigorously develop green agriculture and ecological agriculture, provide farmers with the scientific guidance of pesticides, fertilizers, plastic films and other materials. Finally, the government should increase the promotion of agricultural production models such as circular agriculture and ecological agriculture. The government of Hubei province needs to give support and necessary supervision on technology and capital as well as planting and market, then gradually eliminate backward agricultural production mode, so as to achieve the ecological development of agricultural production.

\section{Conclusions}

At present, the development of agricultural economy in Hubei has entered a new stage. For various subjective and objective reasons, the agricultural economic development in this area has encountered many problems, which has made the speed and quality of agricultural economy development been influenced. This paper puts forward that the development of agricultural economy in Hubei province needs to adhere to the road of scientific and technological agriculture, agricultural industrialization, scale management and ecological agriculture. To achieve this goal, all these aspects need to be taken into consideration; the lack or weakness of any one will seriously affect the healthy development of the agricultural economy. Based on the above basic development direction, Hubei province also should pay attention to institutional innovation, make developmental plan, and smoothly achieve the goal of agricultural economic development by the construction of agricultural technology extension system, land circulation and circular agriculture.

\section{References}

[1] Federal Crop Insurance: Background. Shields, D. A. CRS R 40532. 2015

[2] Achievements and Challenges in Improving the Nutritional Quality of Food Legumes[J] . Maria C. Vaz Patto, Ryszard Amarowicz, Alberta N. A. Aryee, Joyce I. Boye, Hyun-Jung Chung, Maria A. Martín-Cabrejas, Claire Domoney. Critical Reviews in Plant Sciences. 2015 (1-3)

[3] Understanding the rapid spread of System of Rice Intensification (SRI) in Andhra Pradesh: Exploring the building of support networks and media representation[J]. Soutrik Basu, Cees Leeuwis. Agricultural Systems. 2012

[4] Farm Safety Net Programs: Issues for the Next Farm Bill. Shields, D. A, Monke, J, Schnepf, R. CRS Report for Congress. 2010

[5] Sustainability indicators: geology meets economy[J].H.Wiggering, K. Rennings. Environmental Geology. 1997 (1) 